\title{
The ever-broadening field of application of transcatheter pulmonary valves
}

\author{
Christoph Haller, MD
}

\footnotetext{
From The Labatt Family Heart Centre, Department of Cardiovascular Surgery, The Hospital for Sick Children, University of Toronto, Toronto, Ontario, Canada.

Disclosures: Author has nothing to disclose with regard to commercial support.

Received for publication Nov 28, 2017; accepted for publication Dec 4, 2017; available ahead of print Feb 13, 2018.

Address for reprints: Christoph Haller, MD, Division of Cardiovascular Surgery, The Hospital for Sick Children, 555 University Ave, Toronto M5G 1X8, Ontario, Canada (E-mail: christoph.haller@sickkids.ca).

J Thorac Cardiovasc Surg 2018;155:1725-6

$0022-5223 / \$ 36.00$

Copyright (c) 2017 by The American Association for Thoracic Surgery

https://doi.org/10.1016/j.jtcvs.2017.12.019
}

Pulmonary valve replacement in patients with congenital heart disease is a success story, but not only because of the ingenuity of the technique or the revolutionary changes in surgical management. It is a success story because it exemplifies how many congenital cardiac patients reach adulthood. Bioprosthetic valve (BPV) replacement has become a routine procedure in patients with previously repaired tetralogy of Fallot, and the numbers of pulmonary valve replacements are on the rise. ${ }^{1}$ However, counseling the postoperative patient with pulmonary valve regurgitation is complex, as the routine and perceived safety of the procedure have to be weighed against a small but relevant mortality and morbidity: Although a procedure with a perioperative mortality of $1 \%$ can be considered a safe operation from a surgeon's perspective, this safety is put into perspective when seen from the standpoint of a 30-year-old father of a family who has been asymptomatic ever since he can remember. The introduction of transcatheter pulmonary valve replacement with the Melody valve (Medtronic, Minneapolis, Minn) has offered a very valuable option for these patients to avoid surgery and delay the need for surgical-valve replacement. ${ }^{2}$

In this issue of the Journal, Cabalka and colleagues ${ }^{3}$ present a retrospective analysis of valve-in-valve implantations of the Melody valve in deteriorated BPVs of various sizes. Their results are encouraging. With the use of 18- to 22-mm delivery systems, they achieved similar right ventricular outflow tract gradients in patients with $\leq 23$-mm and $\geq 25$ $\mathrm{mm}$ BPVs both at discharge and at follow-up. Even though mean follow-up was only 12 months, valve function remained stable during this time. Gradients seemed to be favorable with little difference if implanted into smaller BPVs. It is surprising, nonetheless, that an 18-mm bovine jugular vein conduit, ie, the largest available Melody valve, does not lead to a greater postimplantation right ventricular outflow tract gradient compared with the postoperative gradient after surgical replacement of a 29-mm BPV. The division into groups with BPVs $\leq 23 \mathrm{~mm}$ and $\geq 25 \mathrm{~mm}$

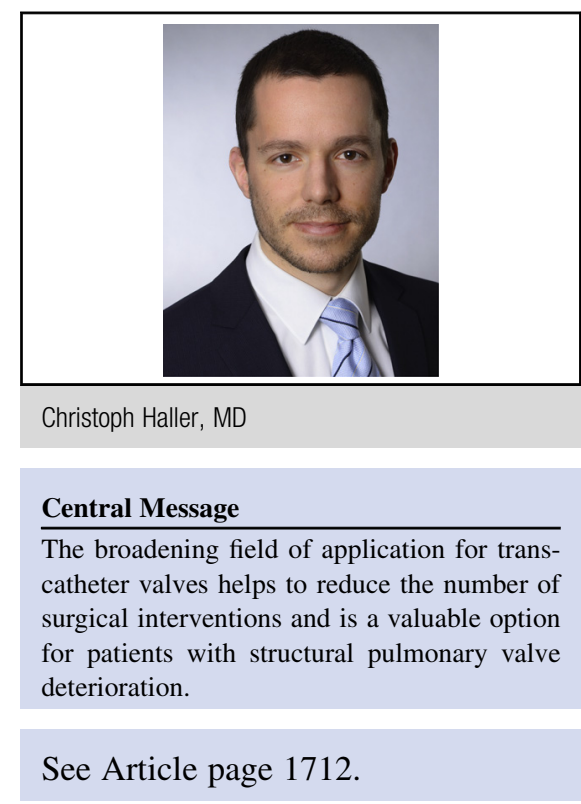

makes the results in very small or very large BPVs difficult to interpret, as $53.6 \%$ of patient had either a 23 - or a $25-\mathrm{mm}$ BPV, but only $18.6 \%$ had BPVs $<21$ or $>27 \mathrm{~mm}$. It is unclear whether the convenience of transcatheter valve-invalve replacement comes at the expense of earlier rereplacement of the conduit, especially in patients at both ends of the spectrum.

A greater risk of endocarditis of bovine jugular vein conduits, as compared with other pulmonary valve prostheses, has been shown previously. ${ }^{4,5}$ Although it is encouraging that the authors did detect only 1 case of prosthetic valve endocarditis, the incidence is still within the reported rates and should not lead to enthusiasm. ${ }^{4,6,7}$ The importance of previous endocarditis needs to be interpreted even more cautiously. Only 4 patients had endocarditis before Melody valve implantation, some of them treated with surgical-valve replacement. The data are insufficient to conclude that previous endocarditis should not be a major factor in the decision-making process. The conclusion is inappropriately phrased and trivializes the risk of a valve-in-valve procedure based on a lack of clinical evidence.

Nevertheless, this should not belittle the advantages of transcatheter pulmonary valve replacement. The most common complication of Melody valve implantations, conduit rupture, ${ }^{8}$ is unlikely to occur in the setting of a BPV. Furthermore, with increasingly low thresholds for 
pulmonary valve replacement in patients after tetralogy of Fallot repair, patients are younger at the time of the first valve replacement and with the implantation of a smaller prosthesis at greater risk of structural valve deterioration and subsequent repeat replacements. ${ }^{9}$ As the Melody valve can be successfully used to avoid some of the surgical-valve replacements in repaired congenital patients, it can add significant benefit to patients who are in the prime of their lives.

\section{References}

1. Moons P, Bovijn L, Budts W, Belmans A, Gewillig M. Temporal trends in survival to adulthood among patients born with congenital heart disease from 1970 to 1992 in Belgium. Circulation. 2010;122:2264-72.

2. Bonhoeffer P, Boudjemline Y, Saliba Z, Merckx J, Aggoun Y, Bonnet D, et al. Percutaneous replacement of pulmonary valve in a right-ventricle to pulmonaryartery prosthetic conduit with valve dysfunction. Lancet. 2000;356:1403-5.

3. Cabalka AK, Asnes JD, Balzer DT, Cheatham JP, Gillespie MJ, Jones TK, et al. Transcatheter pulmonary valve replacement using the melody valve for treatment of dysfunctional surgical bioprostheses: a multicenter study. J Thorac Cardiovasc Surg. 2018;155:1712-24.

4. Malekzadeh-Milani S, Ladouceur M, Iserin L, Bonnet D, Boudjemline Y. Incidence and outcomes of right-sided endocarditis in patients with congenital heart disease after surgical or transcatheter pulmonary valve implantation. $J$ Thorac Cardiovasc Surg. 2014;148:2253-9.

5. Albanesi F, Sekarski N, Lambrou D, Von Segesser LK, Berdajs DA. Incidence and risk factors for Contegra graft infection following right ventricular outflow tract reconstruction: long-term results. Eur J Cardiothorac Surg. 2014;45:1070-4.

6. Jonas RA. Endocarditis and the transcatheter pulmonary valve. J Thorac Cardiovasc Surg. 2014;148:2259-60.

7. McElhinney DB, Benson LN, Eicken A, Kreutzer J, Padera RF, Zahn EM. Infective endocarditis after transcatheter pulmonary valve replacement using the melody valve: combined results of 3 prospective north american and European studies. Circ Cardiovasc Interv. 2013;6:292-300.

8. Chatterjee A, Bajaj NS, McMahon WS, Cribbs MG, White JS, Mukherjee A, et al. Transcatheter pulmonary valve implantation: a comprehensive systematic review and meta-analyses of observational studies. J Am Heart Assoc. 2017;6: e006432.

9. Buber J, Assenza GE, Huang A, Valente AM, Emani SM, Gauvreau K, et al. Durability of large diameter right ventricular outflow tract conduits in adults with congenital heart disease. Int J Cardiol. 2014;175:455-63. 